\title{
Temporal Dermoid Cyst with Unusual Imaging Appearance: Case Report
}

\author{
Khansa ABDERRAHMEN, Asma BOUHOULA, Lasaad AOUIDJ, Hafedh JEMEL \\ National Institute of Neurology of Tunis, Department of Neurosurgery, Tunisia
}

\section{ABSTRACT}

Intracranial dermoid cysts are benign, slow growing tumors derived from ectopic inclusions of epithelial cells during closure of neural tube. These lesions, accounting for less than $1 \%$ of intracranial tumors, have characteristic computed tomography (CT) and magnetic resonance imaging (MRI) appearances that generally permits preoperative diagnosis. However, the radiologic features are uncommon and the cyst can be easily misdiagnosed with other tumors in rare cases. Herein, we report a case of a left temporoparietal dermoid cyst in a 48-year-old woman that was peroperatively and histopathologically proven but not advocated on CT and MRI. Clinical, radiological and histopathological features of a dermoid cyst are reviewed.

KEYWORDS: Dermoid cyst, Brain, Magnetic resonance imaging

\section{INTRODUCTION}

Dermoid cysts are benign dysembryogenic tumors originating from ectopic inclusions of epithelial cells during closure of neural tube. They account for about 0.04 to $0.7 \%$ of all intracranial tumors (20) with a predilection in the cranial midline, the parasellar and sylvian cisterns $(2,9,27)$. Commonly dermoid cysts have characteristic computed tomography (CT) and magnetic resonance imaging (MRI) features making their preoperative diagnosis straightforward although this was not possible in our case.

\section{- CASE REPORT}

A 48-year-old female, with no past medical history, was referred to our department with complaints of headache, vomiting and visual disturbances that started six months prior to admission.

On presentation, the patient was having no neurological deficit. Her general physical and systemic examinations were also normal. A CT of the brain showed a heterogeneous isohypodense left temporo-parietal lesion with an osteoma in front of it and some peripheral calcifications. No surrounding edema and no contrast enhancement were noted. There was a mass effect in the form of effacement of the left occipital horn and moderate midline shift (Figure 1). On MRI study, the lesion appeared to be extra-axial and getting in touch with an osteoma. Mass, measuring $55 \times 40 \times 52 \mathrm{~mm}$, displayed high signal intensity on T2 weighted images and a low signal intensity on $\mathrm{T} 1$ weighted images (Figure 2A-C). There were many peripheral low signal abnormalities on flash $2 d$ images suggesting calcifications (Figure 3). T1 weighted images with Gadolinium showed peripheral enhancement. There was no surrounding edema. Radiologically, the mass does not resemble a special tumor and it was difficult to advocate a preoperative diagnosis (Figure 4).

At surgery, a left temporoparietal craniotomy was done. We first noted the osteoma at the inner surface of the bone that erodes the dura. The tumour was extra-axial, well circumscribed, pearly white in colour, soft in consistency and avascular. It was completely removed. The tumor capsule was also separated from normal brain and excised. The presence of hair and pultaceous material within the tumor could make the surgical diagnosis of a dermoid tumor and this was confirmed by histological studies. The patient postoperative 

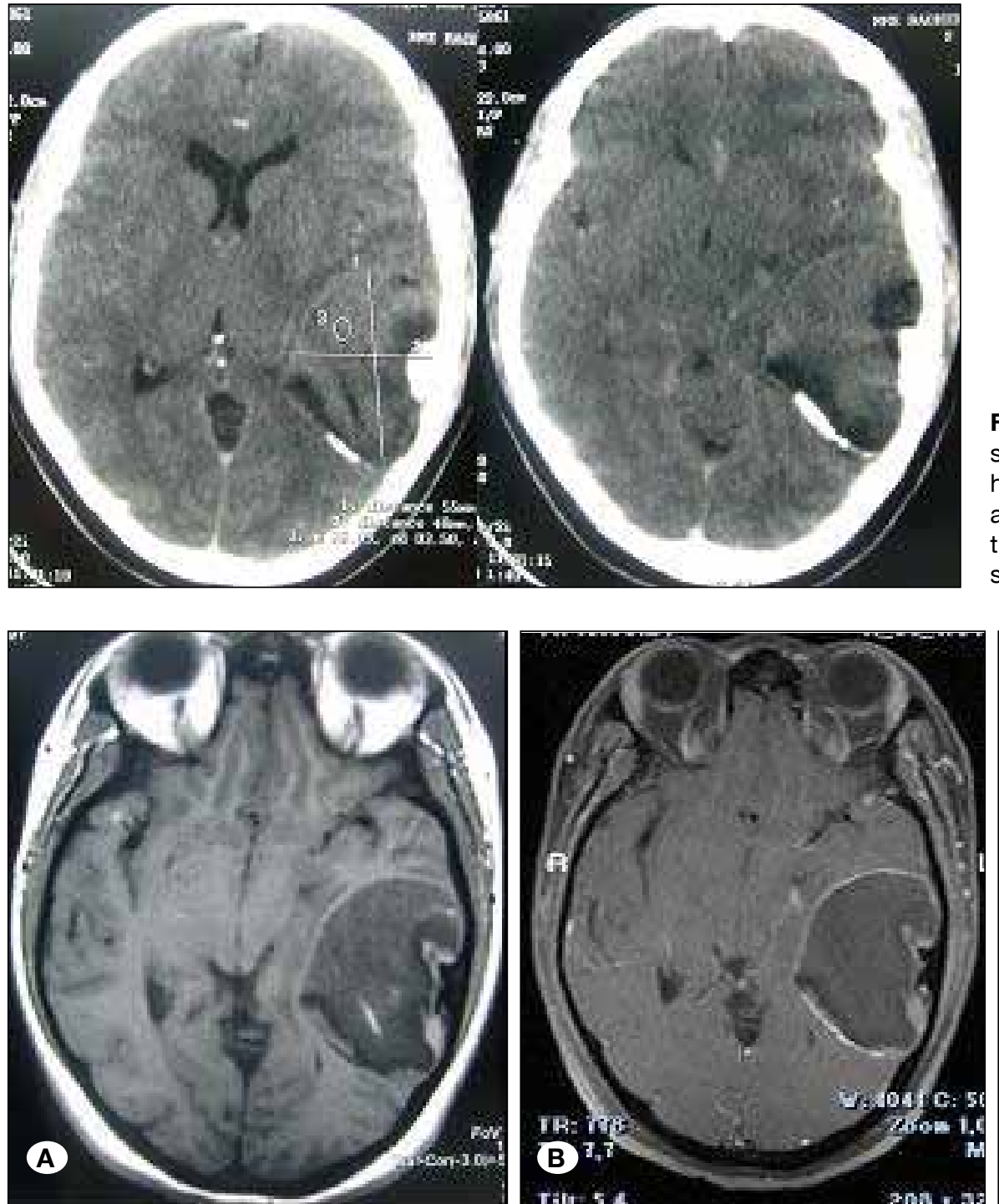

Figure 2: $\mathrm{T} 1$ weighted $\mathrm{MRI}$ images of $\mathbf{A}$ ) axial, B) axial post-contrast and C) coronal post-contrast. The lesion displayed low signal intensity on $\mathrm{T} 1$ weighted images and showed a peripheral enhancement.

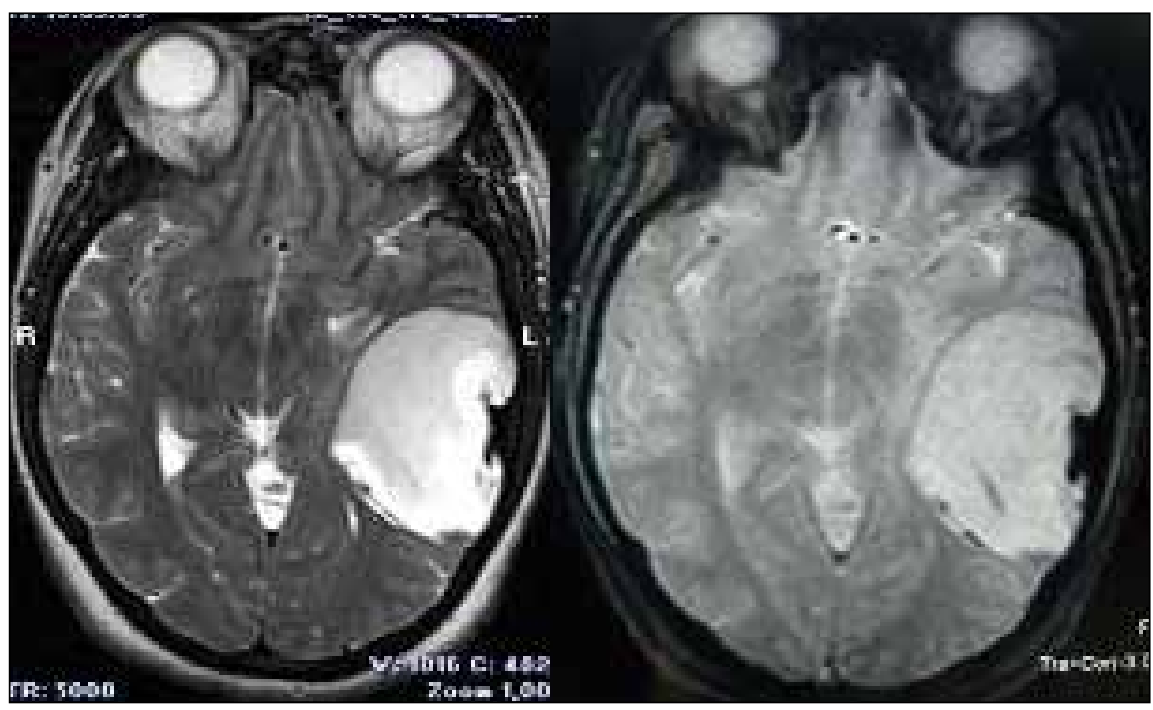

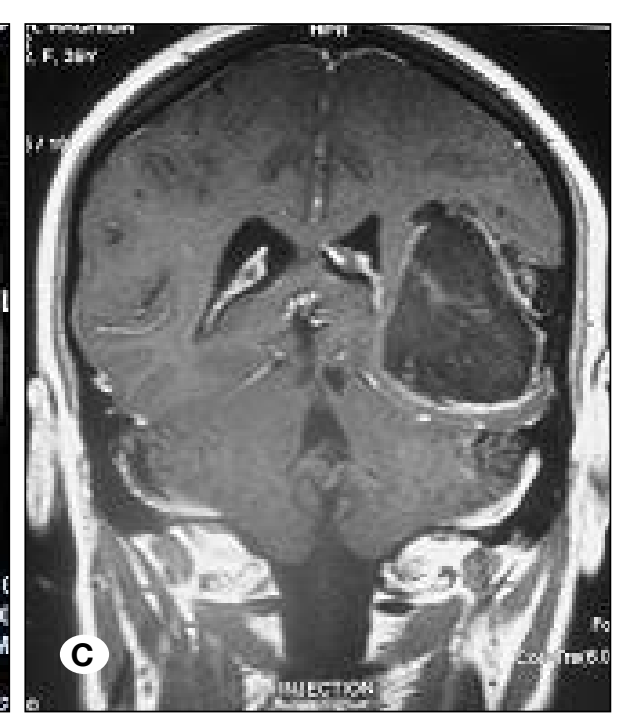

Figure 1: Axial CT scan with contrast, showing a well circumscribed iso- to hypodense left temporoparietal lesion having a calcified rim and an osteoma in front of it, there is no contrast enhancement and no surrounding edema.
Figure 3: High signal intensity on T2 weighted images and many peripheral low signal abnormalities on flash $2 \mathrm{~d}$ images suggesting calcifications. 


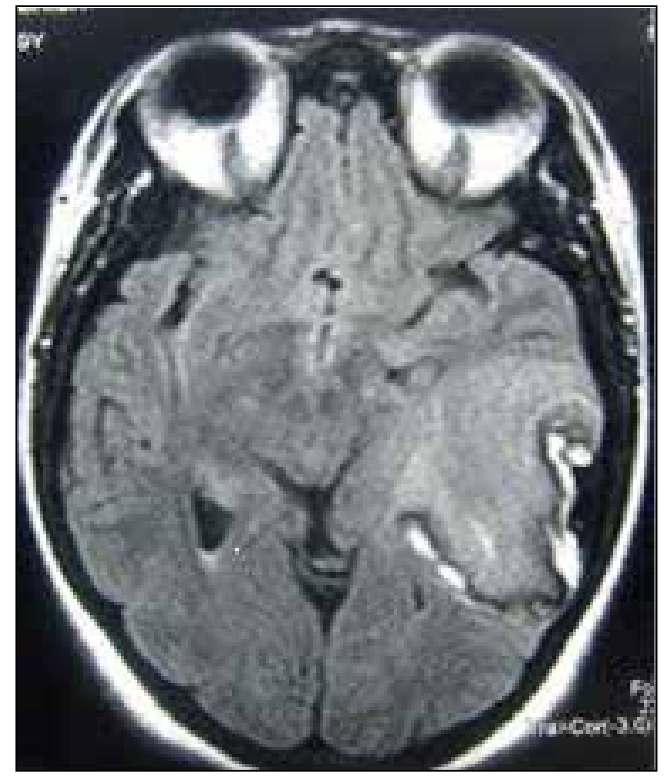

Figure 4: High signal intensity on FLAIR images.

course was uneventful and she was discharged three days after operation without neurological deficit. A CT scan done one month after surgery had confirmed the total removal of the mass. The patient was symptom free during a 10-month follow-up.

\section{DISCUSSION}

Dermoid cysts are regarded as dysembryogenic tumors that derive from ectodermal inclusions of primitive pluripotent cells into the neural tube at around the $5^{\text {th }}$ week of fetal life (21). These lesions accounting for less than $1 \%$ of all intracranial tumors may occur at many levels with the most common sites in the midline but also in the parasellar and sylvian areas $(2,9,27)$. Despite their congenital origin, intracranial dermoids commonly present in the third decade of life with a long history of vague symptoms predominated by headache. Some are associated with seizures, focal neurological deficits, and rarely the rupture of the cyst and the dissemination of intra-cystic contents can cause an aseptic meningitis or ventriculitis with sometimes a dramatic presentation, a more significant morbidity $(5,7,16,17,24,27)$ and even death (14). Nevertheless, dermoid cyst remains a benign tumor, arising from more than one germ layer at a later stage, thus it demonstrates on histological examinations both dermal and epidermal elements with a characteristic thick, stratified squamous epithelium cyst wall surrounding a mixed collection of fat, keratin, hair, bone, cartilage, sebaceous and sweet glands $(5,22)$. The accumulation of desquamation products and gland secretions inside the cyst explain its enlargement what means it is not a true neoplasm (28). All these variable contents of the cyst determine its radiological features. On CT scan, dermoids usually appear as a rounded well circumscribed fat density mass with no surrounding edema and typically no contrast enhancement (26). However, some have mixed density (16) and exceptionally they may appear hyper attenuating on CT scan $(6,8,12)$. A thin rim of calcification is frequently present $(11,12)$. Enhancement after contrast administration is rare but has been also reported $(10,12,13,23)$. In atypical cases, mainly once important differentials have been excluded, we emphasise the importance of certain radiological features that are the well circumscribed character of the lesion, its extra-axial site, the absence of surrounding edema and the peripheral site of calcifications if there are any. In those cases and with the goal of achieving a preoperative accurate diagnosis, MRI, with its newer imaging techniques like the use of fat suppression and diffusion images, remains the diagnostic tool of choice $(18,25)$. Typically, the MRI appearance includes high signal intensity on T1-weighted images due to the fat content and a variable signal intensity ranging from hypo to hyperintense on T2-weighted images $(4,26)$. The mixed composition of the tumor with the lipid and cholesterol which collect within the cyst gives it a characteristic non-homogenous appearance (22). The presence of cholesterol can often make them appear hypointense on T2 as well (23). The fat component is hypointense on T2-weighted images similar to subcutaneous fat $(4,11)$ nevertheless this fat content of a dermoid cyst varies widely (19). T2-weighted images are helpful to distinguish extra-axial from intra-axial lesions by detecting a hyperintense peripheral rim separating the tumor from the surrounding parenchyma. On DWI the dermoids are hyperintense to brain parenchyma but demonstrates an ADC that is similar to parenchyma (15). Fat-suppression techniques may be helpful to confirm the presence of fat in the lesion. We found in the literature several cases of dermoid cysts with an unusual imaging appearance mimicking hematoma (1), oligodendroglioma (25), hemangioblastoma with a mural nodule (12) and even thrombosed giant aneurysm (3). Our case is also unusual and resembles to that reported by Velho (25), even though it was an extremely rare intraaxial tumor in Velho's case.

\section{CONCLUSION}

The imaging characteristics of dermoid cysts depend on their contents that vary widely but they commonly appear as a rounded well circumscribed mass with fat characteristics. In rare atypical cases and in the goal to achieve an accurate pre operative diagnosis, we emphasize the importance of certain radiological features that are the character well circumscribed of the lesion, its extra-axial site, the absence of surrounding edema and the peripheral site of calcifications. MRI, with its newer imaging techniques remains the diagnostic tool of choice in those cases.

\section{- REFERENCES}

1. Bizzozero L, Talamonti G, D’Angelo VA, Casadei GP, Arrigoni GL, Collice M: Dermoid cyst mimicking hematoma in the posterior fossa. Clin Neurol Neurosurg 94:61-63, 1992

2. Caldarelli M, Massimi L: Intracranial midline dermoid and epidermoid in children. J Neurosurg 102: 135-7, 2005

3. Canbaz B, Kemerdere R, Ocal E, Tanriverdi T: Intracranial dermoid cyst mimicking a giant thrombosed aneurysm. Neurol India 52: 524-525, 2004 
4. Davidson HD, Ouchi T, Steiner RE: NMR imaging of congenital intracranial germinal layer neoplasms. Neuroradiology 27(4):301303, 1985

5. Diaz MS, Walker ML: The embryogenesis of complex dysraphic malformations: A disorder of gastrulation? Pediatr Neurosurg 18 (5-6): 229-253, 1992

6. Drolshagen LF, Standefer M: Dense dermoid cyst of the posterior fossa. AJNR 12(2):317, 1991

7. El-Bahy K, Kotb A, Galal A, El-Hakim A: Ruptured intracranial dermoid cysts. Acta Neurochir (Wien) 148(4):457-462, 2006

8. Goh GJ, Page RD, Nixon TE: An unusual CT and MR appearance of a posterior fossa dermoid. Eur J Radiol 20: 46-47, 1995

9. Grijseels S, Stadnik T, Bauwens L: CT and MRI findings in ruptured dermoid cyst in the right parasellar cistern: Report of a case. J Belge Radiol 75: 41-43, 1992

10. Hamer J: Diagnosis by computerized tomography of intradural dermoid with spontaneous rupture of the cyst. Acta Neurochir (Wien) 51(3-4):219-226, 1980

11. Hudgins RJ, Rhyner PA, Edwards MSB: Magnetic resonance imaging and management of a pineal region dermoid. Surg Neurol 27:558-562, 1987

12. Jacqueline YB, Andrew PM, Peter JM, Michael FG: Unusual imaging appearance of an intracranial dermoid cyst. AJNR 22: 1970-1972, 2001

13. Jamjoom $A B$, Cummins $B H$ : The diagnosis of ruptured intracranial dermoid cysts. Br J Neurosurg 3(5):609-612, 1989

14. Kim KS, Weinberg PE: Dermoid tumor. Surg Neurol 15:375376, 1981

15. Kucera JN, Roy P, Murtagh R: Ruptured intracranial dermoid cyst manifesting as new onset seizure: A case report. J Radiol Case Rep 5(4):10-18, 2011

16. Liu JK, Gottfried ON, Salzman KL, Schmidt RH, Couldwell WT: Ruptured intracranial dermoid cysts: Clinical, radiographic, and surgical features. Neurosurgery 62(2):377-384, 2008
17. Martin R, Krone A, Schuknecht B: Rapid development of occlusion hydrocephalus by intraventricular fat possibly derived from a reputed dermoid cyst. J Neurol Neurosurg Psychiatry 52:134-135, 1989

18. Orakcioglu B, Halatsch ME, Fortunati M, Unterberg A, Yonekawa Y: Intracranial dermoid cysts: Variations of radiological and clinical features. Acta Neurochir (Wien) 150(12):1227-1234, 2008

19. Rato RF, Pappamikail LB, Rtilal BO, Luiz CV: Dermoid tumor of the lateral wall of the cavernous sinus. Surg Neurol Int 3:10, 2012

20. Rubin G, Scienza R, Pasqualin A, Rosta L, Da Pian R: Craniocerebral epidermoids and dermoids. A review of 44 cases. Acta Neurochir (Wien) 97(1-2):1-16, 1989

21. Schijman E, Monges J, Cragnaz R: Congenital dermal sinuses, dermoid and epidermoid cysts of the posterior fossa. Child Nerv Syst 2: 83-89, 1986

22. Smith AS, Benson JE, Blaser SI, Mizushima A, Tarr RW, Bellon EM: Diagnosis of ruptured intracranial dermoid cyst: Value MR over CT. AJNR 12:175-180, 1991

23. Stephenson TF, Spitzer RM: MR and CT appearance of ruptured intracranial dermoid tumors. Comput Radiol 11(5-6):249-251, 1987

24. Takeuchi H, Kubuto T, Kabuto M: Ruptured suprasellar dermoid cyst presenting of factory delusion (Eigengeruchs erlebnis). Neurosurgery 33:97-99, 1993

25. Velho VL, Khan SW, Agarwal V, Sharma M: Intra-axial CNS dermoid cyst. Asian J Neurosurg 7(1):42-44, 2012

26. Warakaulle DR, Anslow P: Differential diagnosis of intracranial lesions with high signal on T1 or low signal on T2-weighted MRI. Clin Radiol 58(12):922-933, 2003

27. Wilms G, Casselman J, Demarel P: CT and MRI of ruptured intracranial dermoids. Neuroradiology 33: 149-151, 1991

28. Yaşargil MG, Abernathey CD, Sarioglu AC: Microneurosurgical treatment of intracranial dermoid and epidermoid tumors. Neurosurgery 24(4):561-567, 1989 